\title{
Anti-inflammatory effect of Chrysanthemum zawadskii, peppermint, Glycyrrhiza glabra herbal mixture in lipopolysaccharide-stimulated RAW264.7 macrophages
}

\author{
BYOUNG OK CHO ${ }^{1 *}$, JAE YOUNG SHIN ${ }^{2 *}$, HYUN JU KANG ${ }^{3}$, JI HYEON PARK ${ }^{3}$, \\ SUPING HAO ${ }^{3}$, FENG WANG ${ }^{3}$ and SEON IL JANG ${ }^{1,3}$
}

\begin{abstract}
${ }^{1}$ Department of Food Science, Institute of Health Science, Jeonju University, Jeonju-si, Jeollabuk-do 55069;
${ }^{2}$ Department of Food Science and Technology, Jeonbuk National University, Jeonju-si, Jeollabuk-do 54896;

${ }^{3}$ Department of Health Management, Jeonju University, Jeonju-si, Jeollabuk-do 55069, Republic of Korea
\end{abstract}

Received January 4, 2021; Accepted April 19, 2021

DOI: $10.3892 / \mathrm{mmr} .2021 .12171$

\begin{abstract}
The normal inflammatory reaction protects the body from harmful external factors, whereas abnormal chronic inflammation can cause various diseases, including cancer. The purpose of the present study was to investigate the anti-inflammatory activity of a mixture of Chrysanthemum zawadskii, peppermint and Glycyrrhiza glabra (CPG) by analyzing the expression levels of inflammatory mediators, cytokines and transcription factors in lipopolysaccharide (LPS)-stimulated Raw264.7 cells. A nitric oxide assay, ELISA, western blotting and immunofluorescence staining were performed to investigate the anti-inflammatory activity of the CPG mixture. Pretreatment of Raw264.7 cells with CPG inhibited the increase of inflammatory mediators (inducible nitric oxide synthase, cyclooxygenase- 2 and IFN- $\beta$ ) induced by LPS. Additionally, it inhibited the production of pro-inflammatory cytokines (TNF- $\alpha$, IL- 6 and IL-1 $\beta$ ). CPG suppressed LPS-induced phosphorylation of STAT1,

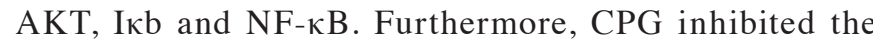
translocation of NF- $\mathrm{KB}$ into the nucleus. In summary, CPG could inhibit LPS-induced inflammation, which occurs primarily through the $\mathrm{AKT} / \mathrm{I} \kappa \mathrm{b} / \mathrm{NF}-\kappa \mathrm{B}$ signaling pathway in RAW264.7 cells.
\end{abstract}

Correspondence to: Professor Seon Il Jang, Department of Health Management, Jeonju University, 303 Cheonjam-ro, Wansan-gu, Jeonju-si, Jeollabuk-do 55069, Republic of Korea

E-mail: sonjjang@jj.ac.kr

${ }^{*}$ Contributed equally

Key words: Chrysanthemum zawadskii, peppermint, Glycyrrhiza glabra, anti-inflammation, NF-кB, STAT1, herbal mixture

\section{Introduction}

Inflammation is a protective response to external stimuli such as pathogens, physical damage, and chemicals. It can inactivate or destroy invading organisms to maintain normal tissues (1). The inflammatory reaction begins with the release of arachidonic acid from cell membrane phospholipids. Through lipoxygenase or cyclooxygenase (COX) action, various mediators of inflammatory reactions such as leukotriene, thromboxane, and prostaglandin are produced (2). These mediators also include nitric oxide (NO), prostaglandin E2 $\left(\mathrm{PGE}_{2}\right)$, and inflammatory cytokines (3). Moderate amounts of NO can kill bacteria or tumors. However, excessive NO production by iNOS can aggravate inflammatory responses, causing tissue damage, genetic mutation, and nerve damage (4). $\mathrm{PGE}_{2}$, one of major mediators of inflammatory responses, contributes to tumor formation by inhibiting apoptosis and inducing angiogenesis (5). Cyclooxygenase (COX) is an enzyme that can promotes the transformation of arachidonic acid into prostaglandin. In particular, COX-2 is induced by various stimulations of inflammation, growth factors, and cytokines caused by cancer cells (6). Tumor necrosis factor (TNF- $\alpha$ ), interleukin (IL-6), and IL-1 $\beta$ are typical pro-inflammatory cytokines whose expression levels are increased during inflammatory reactions. Macrophages secrete them to mediate various inflammatory reactions and induce $\mathrm{NO}$ and $\mathrm{PGE}_{2}$ production (7). Normal inflammatory reaction protects the body. However, when inflammation continues and progresses to chronic inflammation, cancer can develop due to excessive secretion of inflammatory mediators. Insulin resistance can also increase, thereby acting as a mediator of diabetes and various diseases $(8,9)$. Therefore, effective methods for controlling inflammation are needed. Nuclear factor kappa-B (NF- $\mathrm{kB}$ ) and mitogen-activated protein kinase (MAPK) are important signaling molecules in the Toll-like receptor (TLR) pathway. Studies are actively underway to control inflammation by inhibiting these molecules (10).

Chrysanthemum zawadskii is a perennial herb of the Asteraceae family. It is cultivated in China, Russia, Mongolia, and Japan. It has been reported that $C$. zawadskii possess 
antioxidant, antifungal, and anti-inflammatory effects (11). Peppermint (Mentha piperita L.), one of the most popular herbal tea, has been used as a folk remedy and alternative medicine to relieve gastritis, enteritis, biliary disorders, indigestion, and flatulence (12). Licorice (Glycyrrhiza glabra), one of the most commonly used herbal medicine, has been found to possess anti-inflammatory, antiviral, and immunomodulatory activities (13). The purpose of this study was to investigate the anti-inflammatory effect of a herbal mix of $C$. zawadskii, peppermint, and G. glabra (CPG) and its mechanism of action in mouse macrophages.

\section{Materials and methods}

Materials. Chrysanthemum zawadskii, Peppermint (Mentha piperita) and Glycyrrhiza glabra were purchased from Kyeondong market. Dulbecco's modified Eagle's medium (DMEM), fetal bovine serum (FBS), and penicillin/streptomycin antibiotics were purchased from Gibco; Thermo Fisher Scientific, Inc. Griess reagent and LPS (L2630) were procured Sigma-Aldrich; Merck KGaA. Quanti-Max ${ }^{\mathrm{TM}}$ WST-8 Cell Viability Assay Kit has gotten from Biomax. Goat anti-mouse IgG $(\mathrm{H}+\mathrm{L})$ Alexa Fluor plus 488 conjugated secondary antibodies were purchased from Invitrogen; Thermo Fisher Scientific, Inc. Enzyme-linked immunosorbent assay (ELISA) kit PGE $_{2}$, TNF- $\alpha$, IL- 6 , and IL- $1 \beta$ were procured from R\&D System. Mouse IFN Beta ELISA Kit (TCM, Serum) was supplied by BL Assay Science. HO-1 activity kit was purchased from Cusabio. Radio-immunoprecipitation assay buffer (RIPA buffer) came from Thermo Fisher Scientific, Inc. Bradford's assay reagent was purchased from Bio-Rad Laboratories, Inc. 5X SDS-PAGE loading buffer was purchased from Biosesang. Antibodies against iNOS, COX-2, p-NF- $\mathrm{B}, \mathrm{p}-\mathrm{I} \kappa \mathrm{B}, \mathrm{p}-\mathrm{Akt}$, p-STAT1, STAT1, and $\beta$-actin were purchased from Santa Cruz Biotechnology, Inc. HO-1 antibody was procured from Abcam. Horseradish peroxidase (HRP)-IgG secondary antibodies and diamidino-2-phenylindole (DAPI) were purchased from Cell Signaling Technology, Inc.

Preparation of CPG (FHH-CZ). Chrysanthemum zawadskii was extracted with distilled water at $85^{\circ} \mathrm{C}$. Peppermint was extracted with $50 \%$ ethanol at $50^{\circ} \mathrm{C}$. Glycyrrhiza glabra was extracted with distilled water at $50^{\circ} \mathrm{C}$. All plant materials were extracted for $6 \mathrm{~h}$. These extracts were filtered twice, concentrated, and freeze-dried. Glycyrrhiza glabra extract was mixed with $40 \%$ dextrin before freeze-drying. Freeze-dried samples were stored at $4^{\circ} \mathrm{C}$ before experiments. The CPG mixing ratio was Chrysanthemum zawadskii 15: Peppermint 75: Glycyrrhiza glabra 10. The mixture was named FHH-CZ.

Cell culture. RAW264.7 cells (ATCC, SC-6003) were cultured in DMEM supplemented with $10 \%$ FBS and $1 \%$ penicillin/streptomycin antibiotics at $37^{\circ} \mathrm{C}$ with $5 \% \mathrm{CO}_{2}$ in an incubator. These cells were not serum-starved for all experiments.

Cell viability. RAW264.7 cells $\left(2 \times 10^{5}\right.$ cells $\left./ \mathrm{ml}\right)$ were cultured in 96-well plates for $24 \mathrm{~h}$. CPG was used to treat cells at various concentrations $(0 \mu \mathrm{g} / \mathrm{ml} \sim 500 \mu \mathrm{g} / \mathrm{ml})$. After incubating for 20 h, $10 \mu \mathrm{l}$ of Quanti-MaxTM was added. After $4 \mathrm{~h}$ of further incubation, the absorbance of each well was measured using a spectrophotometer (Tecan) at $450 \mathrm{~nm}$. The absorbance of each well conformed to RAW264.7 cell viability.

Nitric oxide assay. RAW264.7 cells $\left(2 \times 10^{5}\right.$ cells $\left./ \mathrm{ml}\right)$ were seeded into a 96-well plate and incubated for $24 \mathrm{~h}$. These cells were then treated with CPG $(0,50,100,200 \mu \mathrm{g} / \mathrm{ml})$ for $1 \mathrm{~h}$ and then stimulated with LPS $(1 \mu \mathrm{g} / \mathrm{ml})$ for $16 \mathrm{~h}$. After stimulation, $100 \mu \mathrm{l}$ of Griess reagent was mixed with $100 \mu \mathrm{l}$ of supernatant and incubated at room temperature (RT) for $15 \mathrm{~min}$. The absorbance at $540 \mathrm{~nm}$ was measured using a spectrophotometer (Tecan). $\mathrm{NaNO}_{2}$ standards were diluted and used to determine $\mathrm{NO}$ concentration.

Assay of cytokine production. RAW264.7 cells ( $2 \times 10^{5}$ cells $\left./ \mathrm{ml}\right)$ were cultured in $60 \mathrm{~mm}$ cell culture dishes for $24 \mathrm{~h}$, treated with CPG $(0,50,100,200 \mu \mathrm{g} / \mathrm{ml})$, and then incubated for $1 \mathrm{~h}$ in an incubator. After that, cells were stimulated with LPS $(1 \mu \mathrm{g} / \mathrm{ml})$ for $16 \mathrm{~h}$. Cell culture supernatant was then obtained to measure levels of $\mathrm{PGE}_{2}$ (R\&D KGE004B), TNF- $\alpha$ (R\&D MTA00B), IL-6 (M6000B) and IL-1 $\beta$ (MLB00C). Using ELISA kits following the manufacturer's protocol without modification.

Protein extraction and western blot. Raw264.7 cells $\left(2 \times 10^{5}\right.$ cells $\left./ \mathrm{ml}\right)$ were cultured in $60 \mathrm{~mm}$ cell culture dishes for $24 \mathrm{~h}$, treated with CPG $(0,50,100,200 \mu \mathrm{g} / \mathrm{ml})$, and incubated for $1 \mathrm{~h}$ in an incubator. After that, cells were stimulated with LPS $(1 \mu \mathrm{g} / \mathrm{ml})$ for $16 \mathrm{~h}$. Whole proteins were then extracted from each sample using protease and phosphatase inhibitors treated-RIPA buffer. After quantification using Bradford protein analysis, proteins $(30 \mu \mathrm{g})$ present in each sample were separated for $1 \mathrm{~h}$ at $100 \mathrm{~V}$ on $12 \%$ polyacrylamide gels. After separation, proteins were transferred onto PVDF membranes for $1 \mathrm{~h}$ at $100 \mathrm{~V}$. After blocking with $5 \%$ bovine serum albumin (BSA) for $1 \mathrm{~h}$, membranes were washed three times with TBST solution (10 min each wash) and then incubated with each antibody (iNOS, COX-2,

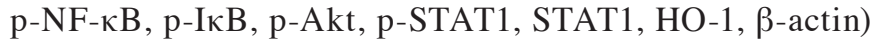
at $4^{\circ} \mathrm{C}$ overnight. Membranes were washed three times with TBST solution for $10 \mathrm{~min}$ and then incubated with mouse or rabbit HRP-conjugated secondary antibodies containing BSA for $2 \mathrm{~h}$ at RT. Subsequently, membranes were washed three times with TBST solution for $10 \mathrm{~min}$ and visualized with an imaging system (Alliance version 15.11; UVITEC) using EZ-western Lumi Pico Alpha chemiluminescent reagent. Band densities were analyzed using ImageJ (developed by the National Institutes of Health) and converted into a graph.

Immunofluorescence. RAW264.7 cells $\left(2 \times 10^{5}\right.$ cells $\left./ \mathrm{ml}\right)$ were cultured in 4-well cell culture slides for $24 \mathrm{~h}$. These cells were then treated with CPG $(0,50,100,200 \mu \mathrm{g} / \mathrm{ml})$, incubated for $1 \mathrm{~h}$ in an incubator, and then stimulated with LPS $(1 \mu \mathrm{g} / \mathrm{ml})$ for $16 \mathrm{~h}$. Next, cells were fixed in ice cold methanol for $10 \mathrm{~min}$ at RT. Slides were washed three times with PBS. After that, slides were incubated with PBS containing $1 \%$ BSA for $1 \mathrm{~h}$ to prevent non-specific antibody binding. After that, slides were incubated at $4^{\circ} \mathrm{C}$ overnight with antibodies $(\mathrm{NF}-\kappa \mathrm{B}, \mathrm{p} 65)$ in $1 \% \mathrm{BSA}$. Incubated slides were washed three times with PBS. After that, slides were incubated with Alexa Fluor 488-conjugated goat 

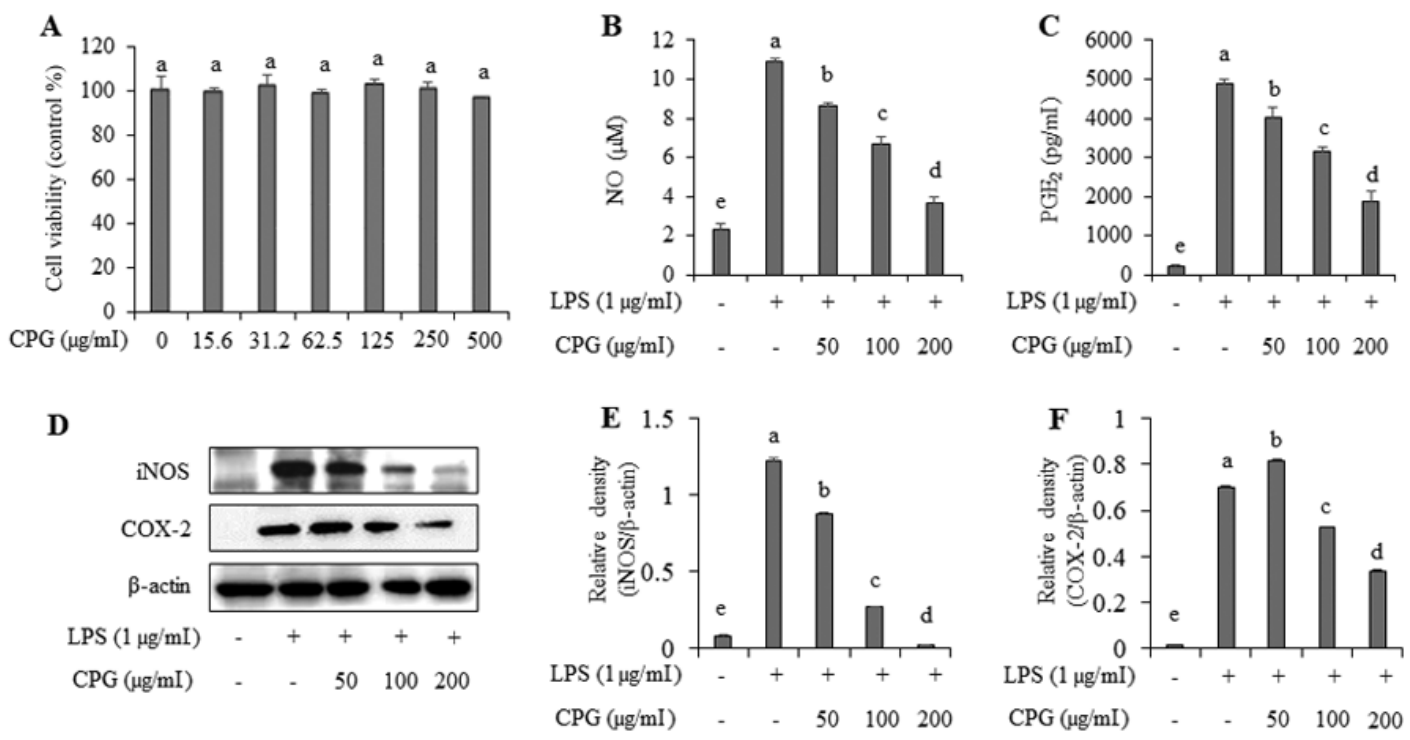

Figure 1. Effects of CPG on cell viability, NO levels, PGE $_{2}$ levels, iNOS and COX-2 expression in LPS-stimulated RAW264.7 macrophages. (A) RAW264.7 cells were treated with CPG at the indicated concentrations for $24 \mathrm{~h}$ and relative cell viability was assessed using a WST-1 assay. RAW264.7 cells were pretreated with CPG at the indicated concentrations and stimulated with LPS for $16 \mathrm{~h}$. Levels of (B) NO and (C) PGE $\mathrm{B}_{2}$ in the culture supernatants were analyzed using a Griess assay and ELISA, respectively. (D) iNOS and COX-2 expression was determined by western blot analysis. (E) Relative density of iNOS was calculated using ImageJ. (F) Relative density of COX-2 was calculated using ImageJ. Data are presented as the mean \pm SD. All groups labelled with the same lower case letter (a-e) were not significantly different from each other $(\mathrm{P}>0.05)$, whereas groups labelled with different lower case letters were significantly different $(\mathrm{P}<0.05)$. CPG, mixture of Chrysanthemum zawadskii, peppermint and Glycyrrhiza glabra; LPS, lipopolysaccharide; NO, nitric oxide; PGE 2 , prostaglandin E2; iNOS, inducible nitric oxide synthase; COX-2, cyclooxygenase-2.

anti-mouse or rabbit $\operatorname{IgG}$ antibody in $1 \% \mathrm{BSA}$ at RT for $1 \mathrm{~h}$. Subsequently, slides were washed with PBS, mounted with DAPI, and photographed under a ZEISS Fluorescence Microscope.

$N F-\kappa B$ DNA-binding activities. NF- $\kappa$ B DNA-binding activities were measured in the nuclear protein extracts using the $\mathrm{NF}-\kappa \mathrm{B}$ transcription factor assay kits. Nuclear extracts $(10 \mu \mathrm{g})$ and complete binding buffer $(0.03 \mathrm{ml})$ were added into wells pre-fixed with NF- $\kappa$ B p65 DNA target and incubated for $1 \mathrm{~h}$ at room temperature with mild agitation. Following the incubation, the wells were washed three times with wash buffers, and $0.1 \mathrm{ml}$ of diluted $\mathrm{NF}-\kappa \mathrm{B}$ antibodies, which recognize only p65 epitopes that are bound to DNA in the wells, was added to each well and incubated for $1 \mathrm{~h}$ at room temperature. Then, the wells were washed as above, and HRP-conjugated antibodies $(0.1 \mathrm{ml})$ were added to each well and incubated for $1 \mathrm{~h}$ at room temperature. Following incubation with the HRP-conjugated antibodies, the wells were washed. $0.1 \mathrm{ml}$ of developing solution was added into the wells for $5 \mathrm{~min}$ and then, the reaction was stopped by adding $0.1 \mathrm{ml}$ of stopping solution. The absorbance, which corresponded with the DNA binding activities, was read at $450 \mathrm{~nm}$ using a spectrophotometer (Tecan).

HO-1 activity. Raw264.7 cells $\left(2 \times 10^{5}\right.$ cells $\left./ \mathrm{ml}\right)$ were cultured in $60 \mathrm{~mm}$ cell culture dish for $24 \mathrm{~h}$. the cells were treated with CPG $(50,100,200 \mu \mathrm{g} / \mathrm{ml})$ or without CPG and incubated for $1 \mathrm{~h}$ in the incubator. After that, the cells were stimulated by LPS $(1 \mu \mathrm{g} / \mathrm{ml})$ for $16 \mathrm{~h}$. After that, whole proteins were extracted from each sample using protease and phosphatase inhibitors treated-RIPA buffer. And enzyme activity was measured using mouse HO-1 ELISA kit.
Statistical analysis. Data are presented as mean \pm SD. Statistically significant differences among groups were determined by one-way analysis of variance (ANOVA) analysis followed by Tukey's post hoc test. $\mathrm{P}<0.05$ was considered statistically significant.

\section{Results}

Effect of CPG on NO level and DPPH radical scavenging activity. Chrysanthemum zawadskii, peppermint and Glycyrrhiza glabra were mixed in various ratios to determine the optimal mixing ratio (Table SI). NO assay and DPPH radical scavenging activity were measured for each mixing ratio. As a result, the No. 5 mixture (Chrysanthemum zawadskii 15: Peppermint 75: Glycyrrhiza glabra 10) showed the highest NO generation inhibitory effect and DPPH radical scavenging activity (Figs. S1 and S2). Therefore, subsequent experiments were conducted using No. 5 Mixture.

$C P G$ inhibits $N O$ and $P G E_{2}$ production in LPS-stimulated RAW264.7 macrophages. To investigate anti-inflammatory effects of CPG in LPS-stimulated RAW264.7 cells, we determined cytotoxic effects of CPG on RAW264.7 cells. After cells were treated with various concentrations $(0,15.6,31.2,62.5$, 125,250 , and $500 \mu \mathrm{g} / \mathrm{ml}$ ) of CPG for $24 \mathrm{~h}$, cell cytotoxicity was investigated. CPG did not cause cytotoxicity to RAW264.7 cells at concentration up to $500 \mu \mathrm{g} / \mathrm{ml}$. Based on such result, we selected concentrations of 50,100 , and $200 \mu \mathrm{g} / \mathrm{ml}$ to study the anti-inflammatory effect of CPG on LPS-stimulated RAW264.7 cells (Fig. 1A). Next, we evaluated effects of CPG treatment on $\mathrm{NO}$ and $\mathrm{PGE}_{2}$ production in LPS-stimulated RAW264.7 cells. We found that LPS treatment significantly 

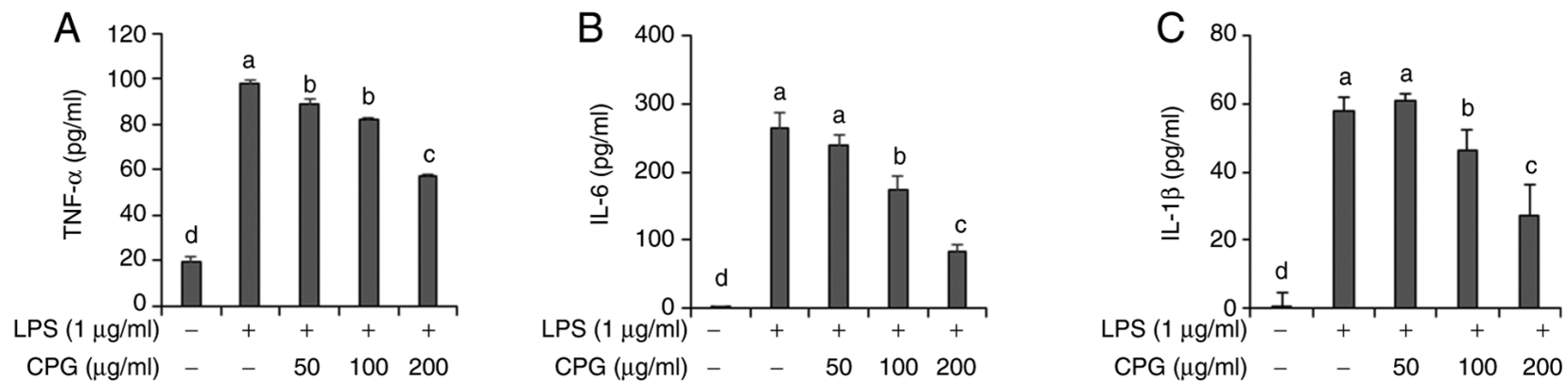

Figure 2. Effect of CPG on TNF- $\alpha$, IL-6 and IL-1 $\beta$ production in LPS-stimulated RAW264.7 macrophages. RAW264.7 cells were pretreated with CPG at the indicated concentrations and stimulated with LPS for $16 \mathrm{~h}$. Levels of (A) TNF- $\alpha$, (B) IL-6 and (C) IL-1 $\beta$ in the culture supernatants were analyzed using an ELISA. Data are presented as the mean \pm SD. All groups labelled with the same lower case letter (a-d) were not significantly different from each other (P $>0.05)$, whereas groups labelled with different lower case letters were significantly different $(\mathrm{P}<0.05)$. CPG, mixture of Chrysanthemum zawadskii, peppermint and Glycyrrhiza glabra; LPS, lipopolysaccharide.

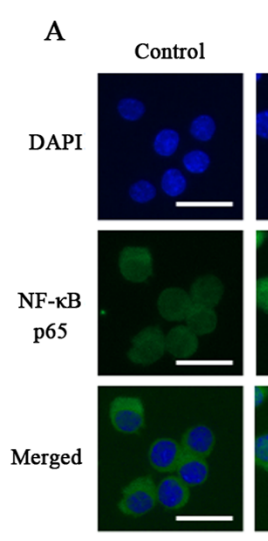

$\mathrm{C}$

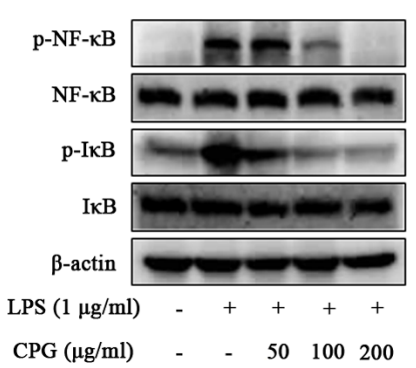

LPS + CPG
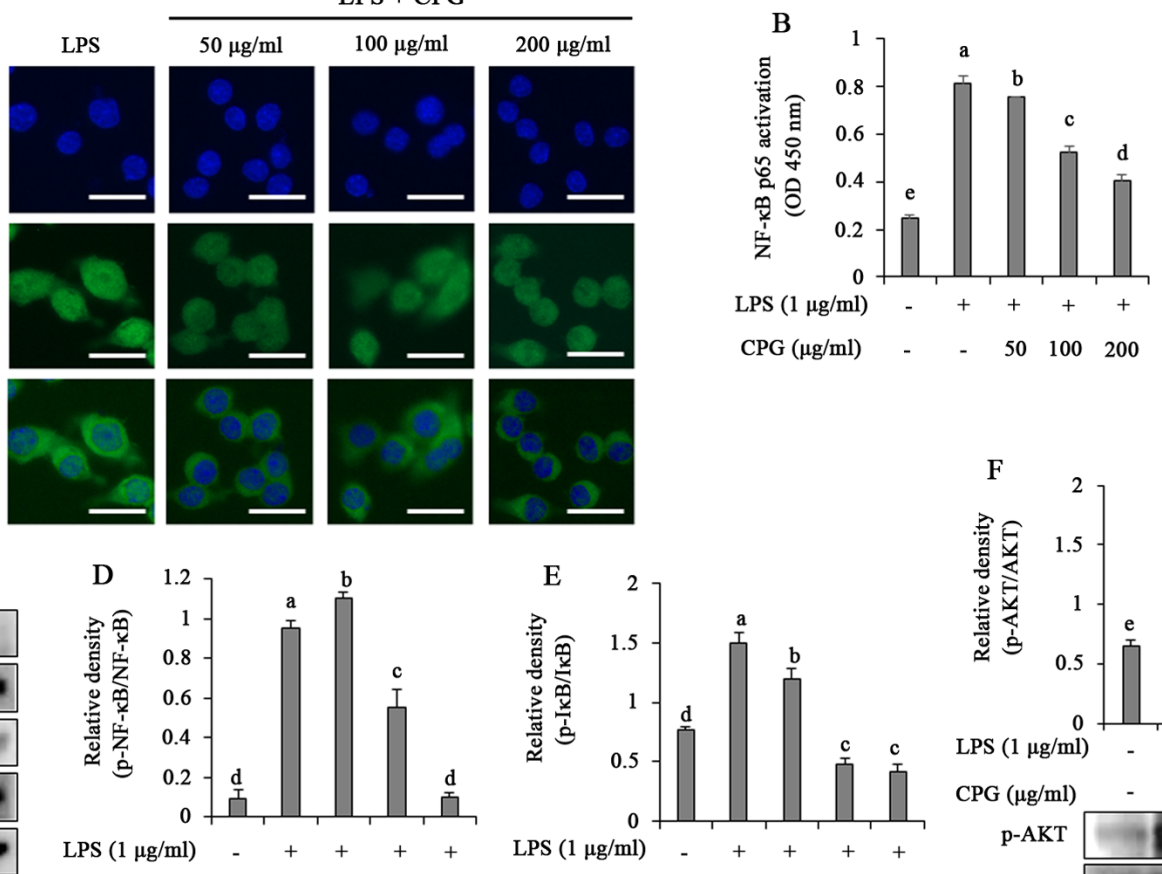

$\mathrm{CPG}(\mu \mathrm{g} / \mathrm{ml}) \quad-\quad-\quad 50 \quad 100200$

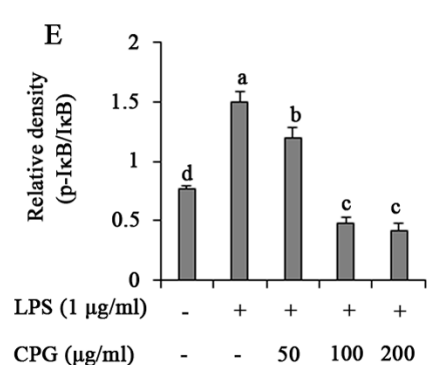

$\mathrm{CPG}(\mu \mathrm{g} / \mathrm{ml}) \quad-\quad-\quad 50 \quad 100200$

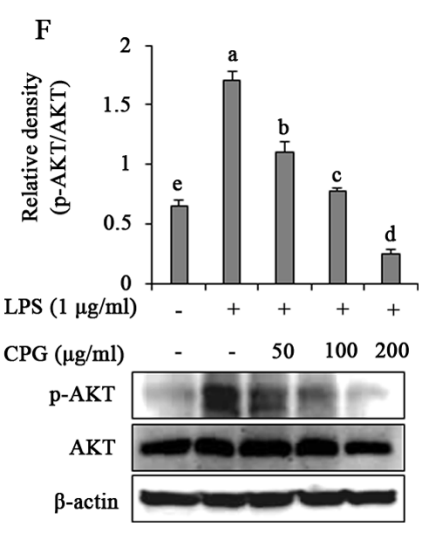

Figure 3. Effects of CPG on LPS-induced NF-kB activation and Akt phosphorylation in RAW264.7 macrophages. RAW264.7 cells were pretreated with $\mathrm{CPG}$ at the indicated concentrations and stimulated with LPS for $30 \mathrm{~min}$. (A) Translocation of NF- $\mathrm{kB}$ p 65 were determined using immunofluorescence. NF- $\mathrm{kB}$ (green) was detected and nuclei were counterstained with DAPI (blue). Scale bar, $10 \mu \mathrm{m}$. (B) DNA binding activity of NF- $\mathrm{BB}$ p65 were determined

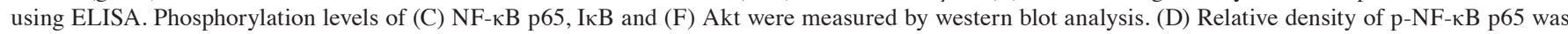
calculated using ImageJ software. (E) Relative density of p-IкB was calculated using ImageJ software. (F) Relative density of p-AKT was calculated using ImageJ software. Data are presented as the mean \pm SD. All groups labelled with the same lower case letter (a-e) were not significantly different from each other ( $\mathrm{P}>0.05)$, whereas groups labelled with different lower case letters were significantly different $(\mathrm{P}<0.05)$. CPG, mixture of Chrysanthemum zawadskii, peppermint and Glycyrrhiza glabra; LPS, lipopolysaccharide; p-, phosphorylated; OD, optical density.

increased NO production in RAW264.7 cells. However, cells pre-treated with CPG before administration of LPS showed significant decreases of $\mathrm{NO}$ and $\mathrm{PGE}_{2}$ production in a dose-dependent manner compared to cells treated with LPS only (Fig. 1B and C).

CPG inhibits iNOS and COX-2 expression levels in LPS-stimulated RAW264.7 macrophages. To investigate inhibitory effects of $\mathrm{CPG}$ on $\mathrm{NO}$ and $\mathrm{PGE}_{2}$ production, we examined iNOS (enzyme generating nitric oxide) and COX-2 (enzyme producing $\mathrm{PGE}_{2}$ ) expression in LPS-stimulated RAW264.7 cells. Results showed that LPS-only treated cells had elevated expression levels of iNOS and COX-2 while cells pre-treated with CPG before administration of LPS showed significant decreases of iNOS and COX-2 expression compared to cells treated with LPS only (Fig. 1D-F).

CPGinhibitsTNF- $\alpha, I L-6$ andIL-1 $\beta$ production in LPS-stimulated RAW264.7 macrophages. Next, we evaluated effects of CPG on the production of pro-inflammatory mediators such as IL-6, 
A

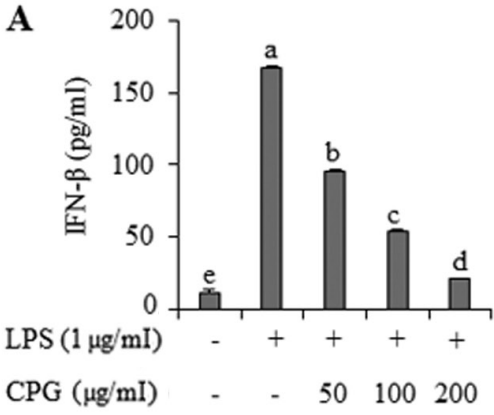

B

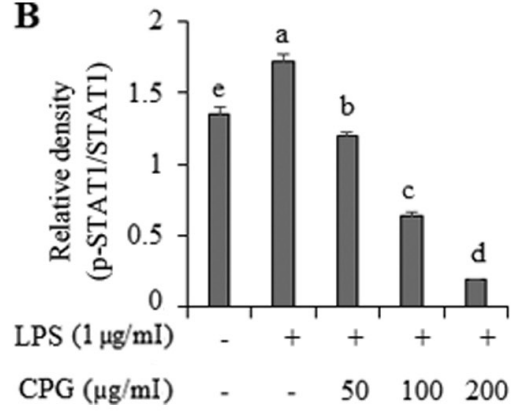

C

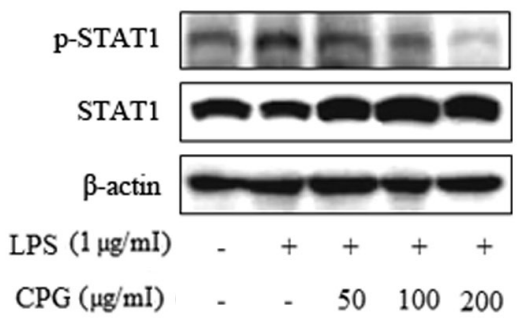

Figure 4. Effects of CPG on IFN- $\beta$ expression and STAT1 activation in LPS-stimulated RAW264.7 macrophages. RAW264.7 cells were pretreated with CPG at the indicated concentrations and stimulated with LPS for 16 h. (A) IFN- $\beta$ expression in culture supernatant was determined using ELISA. RAW264.7 cells were pretreated with CPG at the indicated concentrations and stimulated with LPS for 3 h. (C) STAT1 phosphorylation was determined by western blot analysis. (B) Relative density was calculated using ImageJ software. Data are presented as the mean \pm SD. All groups labelled with the same lower case letter (a-e) were not significantly different from each other $(\mathrm{P}>0.05)$, whereas groups labelled with different lower case letters were significantly different $(\mathrm{P}<0.05)$. CPG, mixture of Chrysanthemum zawadskii, peppermint and Glycyrrhiza glabra; LPS, lipopolysaccharide; p-, phosphorylated.

A

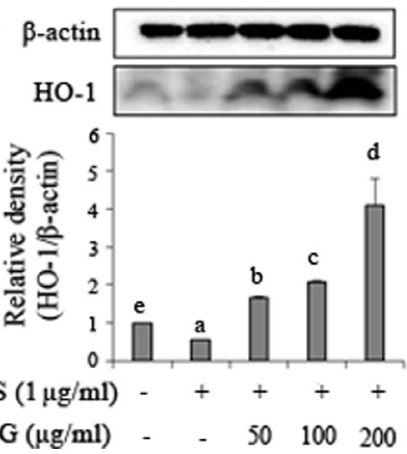

B

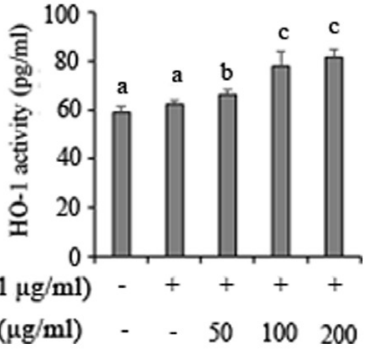

Figure 5. Effects of CPG on HO-1 expression in LPS-stimulated RAW264.7 macrophages. RAW264.7 cells were pretreated with CPG at the indicated concentrations and stimulated with LPS for $16 \mathrm{~h}$. (A) Expression levels of HO-1 were determined by western blot analysis. (B) HO-1 activity was evaluated using an ELISA. Data are presented as the mean \pm SD. All groups labelled with the same lower case letter (a-e) were not significantly different from each other $(\mathrm{P}>0.05)$, whereas groups labelled with different lower case letters were significantly different $(\mathrm{P}<0.05)$. CPG, mixture of Chrysanthemum zawadskii, peppermint and Glycyrrhiza glabra; LPS, lipopolysaccharide; HO-1, heme oxygenase-1.

IL-1 $\beta$, and TNF- $\alpha$ in LPS-stimulated RAW264.7 cells. Results demonstrated that cells treated with LPS only had significantly increased production of IL- 6 , IL- $1 \beta$, and TNF- $\alpha$ cytokines in culture media of cells compared to untreated cells (Fig. 2). However, production levels of TNF- $\alpha$, IL- 6 and IL- $1 \beta$ were found to be decreased in cells pre-treated with 100 or $200 \mu \mathrm{g} / \mathrm{ml}$ of CPG before the administration of LPS (Fig. 2).

$C P G$ inhibits $N F-\kappa B$ and Akt activation in LPS-stimulated RAW264.7 macrophages. To determine molecular mechanisms underlying the anti-inflammatory effects of CPG, we evaluated $\mathrm{NF}-\kappa \mathrm{B}$ pathways in LPS-stimulated RAW264.7 macrophages. As shown in Fig. $3 \mathrm{~A}, \mathrm{NF}-\kappa \mathrm{B}$ p65 subunit was translocated into the nucleus in LPS-stimulated RAW264.7 cells. However, such translocation induced by LPS was markedly suppressed in CPG pretreated RAW264.7 cells. DNA binding activity of NF- $\mathrm{NB}$ was also significantly increased in LPS-stimulated RAW264.7 cells. However, when cells were pre-treated with CPG before administration of LPS, the DNA binding activity of NF- $\kappa$ B was significantly reduced in a dose-dependent manner (Fig. 3B). We further investigated whether CPG affected the phosphorylation of NF- $\mathrm{BB}$ and I $\mathrm{B}$ in LPS-stimulated RAW264.7 cells. Results revealed that cells treated with LPS alone had

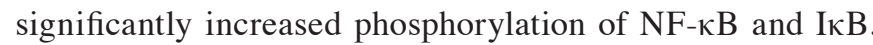

However, phosphorylated NF- $\kappa \mathrm{B}$ and $\mathrm{I} \kappa \mathrm{B}$ were reversed when cells were pre-treated with 50 to $200 \mu \mathrm{g} / \mathrm{ml}$ of CPG before administration of LPS (Fig. 3C-E). We also determined effects of CPG on Akt activation in LPS-stimulated RAW264.7 cells. Akt phosphorylation was significantly increased in cells treated with LPS alone. However, when cells were pre-treated with 50 to $200 \mu \mathrm{g} / \mathrm{ml}$ of CPG before administration of LPS, the phosphorylation of Akt was significantly reduced in a dose-dependent manner (Fig. 3F).

CPG inhibits IFN- $\beta$ production and STAT1 activation in LPS-stimulated RAW264.7 macrophages. Next, we analyzed the effect of CPG on IFN- $\beta$ production in LPS-stimulated RAW264.7 cells. As shown in Fig. 4A, the production of IFN- $\beta$ was significantly increased in cells treated with LPS only. However, cells pre-treated with 50 to $200 \mu \mathrm{g} / \mathrm{ml}$ of CPG before administration of LPS showed a significant and dose-dependent decrease in IFN- $\beta$ production compared to cells treated with LPS only. To further analyze the mechanism of action involved in the effect of CPG on IFN- $\beta$ production, we determined STAT1 activation in LPS-stimulated RAW264.7 cells. As shown in Fig. 4B and C, when cells were treated with LPS alone, the phosphorylation of STAT1 was significantly increased in RAW264.7 cells. However, the phosphorylation of 
STAT1 was significantly decreased when cells were pre-treated with 50 to $200 \mu \mathrm{g} / \mathrm{ml}$ of CPG before administration of LPS.

CPG induces HO-1 expression in LPS-stimulated RAW264.7 macrophages. To further determine anti-inflammatory effects of CPG, we investigated HO-1 expression in LPS-stimulated RAW264.7 cells. As shown in Fig. 5A, cells treated with LPS alone showed slightly reduced HO-1 expression than non-treated cells. However, HO-1 expression was significantly increased when cells were pretreated with 50 to $200 \mu \mathrm{g} / \mathrm{ml}$ of CPG before the administration of LPS. We also investigated HO-1 activity in LPS-stimulated RAW264.7 cells (Fig. 5B). Results showed that HO-1 activity was increased in cells pre-treated with 50 to $200 \mu \mathrm{g} / \mathrm{ml}$ of CPG before the administration of LPS.

\section{Discussion}

As a result of measuring antioxidant and anti-inflammatory effects of C. zawadskii, peppermint, and Glycyrrhiza glabra in our preliminary study, it was confirmed that there was a synergistic effect when these herb were combined than a single substance. Therefore, in the present study, we investigated anti-inflammatory effects of CPG in LPS-treated RAW264.7 cells. LPS can cause inflammation in the human body via excessive production of pro-inflammatory mediators such as NO, $\mathrm{PGE}_{2}$, iNOS, COX-2, TNF- $\alpha$, IL-6, and IL-1 $\beta(14,15)$. In the present study, we found that CPG significantly decreased LPS-elevated $\mathrm{NO}, \mathrm{PGE}_{2}$, iNOS, COX-2 production in RAW264.7 cells. The production of TNF- $\alpha$, IL- 6 and IL- $1 \beta$ in stimulated cells was also suppressed by CPG. Several studies have found that herbal mixture can suppress $\mathrm{NO}, \mathrm{PGE}_{2}$, iNOS, COX-2, TNF- $\alpha$, IL- 6 , and IL- $1 \beta$ in macrophages $(16,17)$. Thus, CPG might be useful for suppressing inflammatory mediators.

The production of pro-inflammatory cytokines by LPS is implicated in the NF- $\mathrm{kB}$ signaling pathway. Therefore, NF- $\mathrm{\kappa B}$ has been studied as a key target in the treatment of inflammation (18). NF- $\kappa B$ activation was investigated in this study to elucidate the precise mechanism involved in the effect of CPG on LPS-induced inflammation in RAW264.7 cells. When LPS is recognized by Toll-like receptor 4 (TLR4), NF- $\kappa B$ is activated through the activation of MyD88 with phosphorylation and decomposition of $\operatorname{I\kappa B} \alpha(19)$. I $\mathrm{K} B \alpha$, an inhibitor of NF- $\kappa \mathrm{B}$, is regulated by I $\mathrm{B}$ kinase (IKK). When activated, $\mathrm{NF}-\kappa \mathrm{B}$ subunit $\mathrm{p} 65$ separates from $\mathrm{I \kappa B} \alpha$ and migrates from the cytoplasm to the nucleus, causing transcription of pro-inflammatory cytokine genes (20). Previous studies have reported the anti-inflammatory effect of a herbal mixture is due to inhibition of NF- $\kappa B$ signaling pathway $(21,22)$. Akt is activated by PI3K. It is involved in the activation of transcription factors including NF- $\mathrm{KB}$ (23). Our results revealed that CPG inhibited the translocation and DNA binding activity of NF- $\kappa B$ in LPS-stimulated RAW264.7 cells. CPG also suppressed the phosphorylation of Akt, IкB, and NF- $\kappa B$ p65 in LPS-stimulated RAW264.7 cells. Results of the present study suggest that the anti-inflammatory effect of CPG might be due to the inactivation of NF- $\mathrm{kB}$, at least in part.

LPS stimulation can induce IFN- $\beta$ production in macrophages through the TRIF/TBK1/IRF3 signaling pathway. IFN- $\beta$ production is related to NF- $\mathrm{KB}$ and MAPK activation (24). STAT1 activation is also required for IFN- $\beta$ production (25). Previous studies have reported that a herbal mixture can attenuate inflammatory responses by suppressing the inhibition of NF- $\kappa \mathrm{B}$ and IFN- $\beta /$ STAT1 activation in macrophages (26). Consistent with previous studies, our results demonstrated that CPG could suppress IFN- $\beta$ production and STAT1 phosphorylation increased by LPS stimulation in RAW264.7 cells. These findings suggest that CPG could suppress inflammatory responses by regulating IFN- $\beta /$ STAT1 activation and NF-kB pathway.

In immune responses, $\mathrm{HO}-1$ plays an important role in the regulation of NO production. HO-1 induction is regulated by Nrf2 transcription factor, a strong antioxidant/anti-inflammatory regulator (27). Our results showed that CPG increased levels of HO-1 expression induced by LPS stimulation in RAW264.7 cells. Many studies have reported that natural products and herbal mixture possess anti-inflammatory activities by regulating Nrf2/HO-1 expression in macrophages $(28,29)$. Therefore, Nrf2 transcription factor needs to be investigated in the future.

Herbal medicine is believed to have less side effects compared to drugs such as chemical counterparts or synthetic anti-inflammatory agents. Its effectiveness has been proven empirically for a long time (30). Anti-inflammatory and antioxidant functions of $C$. zawadskii, peppermint, and licorice have been reported previously (11-13). Linarin, the major bioactive substance of $C$. zawadskii, has been reported to exhibit anti-inflammatory, antioxidant, hepatoprotective, antibacterial, and anticancer activities (31). Limonene, one of major ingredients of peppermint, has been reported to have anti-inflammatory, antioxidant, antibacterial, and anti-cancer effects (32). A previous study has shown that glycyrrhetinic acid exhibits anti-inflammatory effects through NO scavenging in LPS-stimulated RAW264.7 cells (33). Our results also found that linarin, limonene, and glycyrrhetinic acid could inhibit NO production increased by LPS treatment in RAW264.7 cells (data not shown). Therefore, the anti-inflammatory effect of CPG might be due to bioactive substances contained in these three extracts used in the present study.

In conclusion, CPG herbal mixture could suppress the production of NO, iNOS, COX-2, and other pro-inflammatory mediators including PGE 2 , TNF- $\alpha$, IL- 6 , IL1- $\beta$, and IFN- $\beta$ in LPS-stimulated RAW264.7 macrophages. CPG also could suppress LPS-induced inflammation through Akt/NF- $\mathrm{kB}$ and STAT1 signaling pathways in RAW264.7 cells. Moreover, CPG could inhibit LPS-induced inflammation through HO-1 induction in RAW264.7 cells. Results of the present study demonstrates that CPG should be considered as anti-inflammatory natural materials for the treatment of inflammatory diseases. In addition, animal model studies are required to verify whether the effect of $\mathrm{CPG}$, which was shown at the cellular level, appears in animals.

\section{Acknowledgements}

Not applicable.

\section{Funding}

The Ministry of Trade, Industry, and Energy (MOTIE), Korea, under the 'Regional Specialized Industry Development 
Program (grant no. S2913418)' supervised by the Korea Institute for Advancement of Technology (KIAT) financially supported this research.

\section{Availability of data and materials}

The datasets used and/or analyzed during the current study are available from the corresponding author on reasonable request.

\section{Authors' contributions}

BOC and SIJ conceived the study and developed the methodology. SIJ provided resources, reviewed and edited the manuscript, and supervised the study. JYS, HJK, JHP, SH and FW participated in acquisition, analysis and interpretation of data. BOC and JYS wrote the original draft. BOC, JYS and SIJ confirmed the authenticity of all the raw data. All authors read and approved the final manuscript.

\section{Ethics approval and consent to participate}

Not applicable.

\section{Patient consent for publication}

Not applicable.

\section{Competing interests}

The authors declare that they have no competing interests.

\section{References}

1. Cheung RCF, Ng TB, Wong JH, Chen Y and Chan WY: Marine natural products with anti-inflammatory activity. Appl Microbiol Biotechnol 100: 1645-1666, 2016.

2. Funk CD: Prostaglandins and leukotrienes: Advances in eicosanoid biology. Science 294: 1871-1875, 2001.

3. Nathan $C$ : Nitric oxide as a secretory product of mammalian cells. FASEB J 6: 3051-3064, 1992.

4. Weisz A, Cicatiello L and Esumi H: Regulation of the mouse inducible-type nitric oxide synthase gene promoter by interferon-gamma, bacterial lipopolysaccharide and NG-monomethyl-L-arginine. Biochem J 316: 209-215, 1996.

5. Bishop-Bailey D, Calatayud S, Warner TD, Hla T and Mitchell JA: Prostaglandins and the regulation of tumor growth. J Environ Pathol Toxicol Oncol 21: 93-101, 2002.

6. Seibert K, Zhang Y, Leahy K, Hauser S, Masferrer J, Perkins W, Lee $\mathrm{L}$ and Isakson P: Pharmacological and biochemical demonstration of the role of cyclooxygenase 2 in inflammation and pain. Proc Natl Acad Sci USA 91: 12013-12017, 1994.

7. Islam SU, Lee JH, Shehzad A, Ahn EM, Lee YM and Lee YS: Decursinol angelate inhibits LPS-induced macrophage polarization through modulation of the $\mathrm{NF} \kappa \mathrm{B}$ and MAPK signaling pathways. Molecules 23: 1880, 2018.

8. Hofseth LJ and Ying L: Identifying and defusing weapons of mass inflammation in carcinogenesis. Biochim Biophys Acta 1765: 74-84, 2006.

9. Nishida T, Yabe Y, Fu HY, Hayashi Y, Asahi K, Eguchi H, Tsuji S, Tsujii M, Hayashi N and Kawano S: Geranylgeranylacetone induces cyclooxygenase-2 expression in cultured rat gastric epithelial cells through NF-kappaB. Dig Dis Sci 52: 1890-1896, 2007.

10. Hsieh IN, Chang AS, Teng CM, Chen CC and Yang CR: Aciculatin inhibits lipopolysaccharide-mediated inducible nitric oxide synthase and cyclooxygenase-2 expression via suppressing $\mathrm{NF}-\kappa \mathrm{B}$ and $\mathrm{JNK} / \mathrm{p} 38 \mathrm{MAPK}$ activation pathways. $\mathrm{J}$ Biomed Sci 18: 28, 2011 .
11. Kim HS: Extracts of Chrysanthemum zawadskii attenuate oxidative damage to vascular endothelial cells caused by a highly reducing sugar. Cytotechnology 69: 915-924, 2017.

12. McKay DL and Blumberg JB: A review of the bioactivity and potential health benefits of peppermint tea (Mentha piperita L.). Phytother Res 20: 619-633, 2006.

13. Wu L, Fan Y, Fan C, Yu Y, Sun L, Jin Y, Zhang Y and Ye RD: Licocoumarone isolated from Glycyrrhiza uralensis selectively alters LPS-induced inflammatory responses in RAW 264.7 macrophages. Eur J Pharmacol 801: 46-53, 2017.

14. Lee WS, Shin JS, Jang DS and Lee KT: Cnidilide, an alkylphthalide isolated from the roots of Cnidium officinale, suppresses LPS-induced NO, PGE2, IL-1 $\beta$, IL- 6 and TNF- $\alpha$ production by AP-1 and NF- $\kappa$ B inactivation in RAW 264.7 macrophages. Int Immunopharmacol 40: 146-155, 2016.

15. Seo S, Lee KG, Shin JS, Chung EK, Lee JY, Kim HJ and Lee KT: 6'-O-Caffeoyldihydrosyringin isolated from Aster glehni suppresses lipopolysaccharide-induced iNOS, COX-2, TNF- $\alpha$, IL-1 $\beta$ and IL- 6 expression via NF- $\kappa$ B and AP-1 inactivation in RAW 264.7 macrophages. Bioorg Med Chem Lett 26: 4592-4598, 2016.

16. Kang HJ, Hong $\mathrm{SH}$, Kang $\mathrm{KH}$, Park $\mathrm{C}$ and Choi YH: Anti-inflammatory effects of Hwang-Heuk-San, a traditional Korean herbal formulation, on lipopolysaccharide-stimulated murine macrophages. BMC Complement Altern Med 15: 447-447, 2015.

17. Kao ST, Lin CS, Hsieh CC, Hsieh WT and Lin JG: Effects of xiao-qing-long-tang (XQLT) on bronchoconstriction and airway eosinophil infiltration in ovalbumin-sensitized guinea pigs: In vivo and in vitro studies. Allergy 56: 1164-1171, 2001.

18. Wu XL, Liou CJ, Li ZY, Lai XY, Fang LW and Huang WC: Sesamol suppresses the inflammatory response by inhibiting $\mathrm{NF}-\kappa \mathrm{B} / \mathrm{MAPK}$ activation and upregulating AMP kinase signaling in RAW 264.7 macrophages. Inflamm Res 64: 577-588, 2015.

19. Pan H, Xu LH, Ouyang DY, Wang Y, Zha QB, Hou XF and He XH: The second-generation mTOR kinase inhibitor INK128 exhibits anti-inflammatory activity in lipopolysaccharide-activated RAW 264.7 cells. Inflammation 37: 756-765, 2014.

20. Ni W, Zhang Q, Liu G, Wang F, Yuan H, Guo Y, Zhang X, Xie F, Li Q and Tai G: Escherichia coli maltose-binding protein activates mouse peritoneal macrophages and induces M1 polarization via TLR2/4 in vivo and in vitro. Int Immunopharmacol 21: 171-180, 2014.

21. Huang LH, Pan XP, Gong KR and Shao G: Anti-inflammatory effects of three kinds of traditional Mongolian medicine monomer and its combination on LPS-stimulated RAW264.7 macrophages. Eur Rev Med Pharmacol Sci 20: 950-958, 2016.

22. Kalaiselvan S and Rasool MK: Triphala herbal extract suppresses inflammatory responses in LPS-stimulated RAW 264.7 macrophages and adjuvant-induced arthritic rats via inhibition of NF- $\mathrm{B}$ pathway. J Immunotoxicol 13: 509-525, 2016.

23. Cianciulli A, Calvello R, Porro C, Trotta T, Salvatore R and Panaro MA: PI3k/Akt signalling pathway plays a crucial role in the anti-inflammatory effects of curcumin in LPS-activated microglia. Int Immunopharmacol 36: 282-290, 2016.

24. Kawai T and Akira S: Signaling to NF-kappaB by Toll-like receptors. Trends Mol Med 13: 460-469, 2007.

25. Kim HY, Kim JH, So Y, Kang SY, Jeong HG and Jin CH: Anti-inflammatory effect of lupinalbin A isolated from Apios americana on lipopolysaccharide-treated RAW264.7 cells. Molecules 23: 583, 2018.

26. Han YK, Kim YS, Natarajan SB, Kim WS, Hwang JW, Jeon NJ, Jeong JH, Moon SH, Jeon BT and Park PJ: Antioxidant and anti-inflammatory effects of Chaenomeles sinensis leaf extracts on LPS-stimulated RAW 264.7 cells. Molecules 21: 422, 2016.

27. Shinkai Y, Yamanaka I, Duong HH, Quynh NT, Kanaho Y and Kumagai Y: Garcinia vilersiana bark extract activates the Nrf2/HO-1 signaling pathway in RAW264.7 cells. J Toxicol Sci 38: 875-878, 2013.

28. Hong C, Cao J, Wu CF, Kadioglu O, Schüffler A, Kauhl U, Klauck SM, Opatz T, Thines E, Paul NW and Efferth T: The Chinese herbal formula Free and Easy Wanderer ameliorates oxidative stress through KEAP1-NRF2/HO-1 pathway. Sci Rep 7: 11551, 2017.

29. Park JY, Kwon YW, Lee SC, Park SD and Lee JH: Herbal formula SC-E1 suppresses lipopolysaccharide-stimulated inflammatory responses through activation of $\mathrm{Nrf} 2 / \mathrm{HO}-1$ signaling pathway in RAW 264.7 macrophages. BMC Complement Altern Med 17: 374, 2017. 
30. Yatoo MI, Gopalakrishnan A, Saxena A, Parray OR, Tufani NA, Chakraborty S, Tiwari R, Dhama K and Iqbal HMN: Anti-inflammatory drugs and herbs with special emphasis on herbal medicines for countering inflammatory diseases and disorders-a review. Recent Pat Inflamm Allergy Drug Discov 12: 39-58, 2018.

31. Kim KY, Oh TW, Yang HJ, Kim YW, Ma JY and Park KI: Ethanol extract of Chrysanthemum zawadskii Herbich induces autophagy and apoptosis in mouse colon cancer cells through the regulation of reactive oxygen species. BMC Complement Altern Med 19: 274, 2019.

32. Vieira AJ, Beserra FP, Souza MC, Totti BM and Rozza AL: Limonene: Aroma of innovation in health and disease. Chem Biol Interact 283: 97-106, 2018.
33. Zhou JX and Wink M: Evidence for anti-inflammatory activity of isoliquiritigenin, $18 \beta$ glycyrrhetinic acid, ursolic acid, and the traditional chinese medicine plants Glycyrrhiza glabra and Eriobotrya japonica, at the molecular level. Medicines (Basel) 6: $55,2019$.

This work is licensed under a Creative Commons Attribution-NonCommercial-NoDerivatives 4.0 International (CC BY-NC-ND 4.0) License. 